\title{
Salmonella enterica Modulates Its Infectivity in Response to Intestinal Stimuli
}

\author{
Jens Baumbach, Henrike Hoeke, Friderike Weege, Arne Gunnar Schmeisky, \\ Petra Neumann-Staubitz \\ Institute for Microbiology and Genetics, Georg-August-University of Goettingen, Goettingen, Germany \\ Email: pneuman3@gwdg.de
}

Received March 15, 2012; revised April 16, 2012; accepted April 24, 2012

\begin{abstract}
En route to its intestinal target cells Salmonella enterica passes different host niches and encounters various environmental cues. These are expected to promote Salmonella in the decision of changing its extracellular life style to intracellular. We find that prior incubation of bacteria in the presence of signals which are characteristic for the small intestine affects invasion in a model system: Salmonella grown at high osmotic pressure in the presence of bile or in amino acid rich medium, infect host cells most efficiently. Hence, Salmonella enterica modulates its infectivity in response to these stimuli which consequently determines the success of infection. Our results close the current gap between signal and actual behavior and may serve as a basis for further investigations for example if Salmonella has an adaptive prediction of environmental changes.
\end{abstract}

Keywords: Environmental Signal; Intestine; Invasion

\section{Introduction}

The facultative intracellular enterobacterium Salmonella entericaserovar Typhimurium (S. Typhimurium) follows a "default" route when it infects a new host, which includes a switch from an extracellular to an intracellular life style. To timely initiate this crucial step during host colonization, Salmonella needs information from the surrounding milieu. S. enterica enters the human body usually with food via the fecal-oral route. It preferably invades M-cells or other enterocytes to further infect macrophages and deeper lying tissues, a state associated with severe disease [1,2]. Thus, en route to its "entry" cells in the small intestine Salmonella passes environments of different physico-chemical composition. Salmonella faces these environmental cues in a certain temporal order. It is possible that Salmonella has an environmental anticipation and has adapted to it as it has been shown for two model organisms recently [3]. Hence, knowing which environmental cues impact the invasion behavior of salmonella is the first step to understand how an infection is established. Currently we lack the link between certain cues and the invasion behavior of Salmonella although it has been shown that Salmonella responds to environmental stimuli on genetic level $[4,5]$. Here, we investigate the influence of a selection of distinct signals, found in the course of infection, on Salmonella's ability to invade host cells.

\section{Results}

We have chosen the conventional M9 minimal medium (M9MM) as a basic fluid for bacterial culture to separate the effect of single cues. The infection assays were performed incubating the bacteria for a prolonged time in M9MM and subsequently diluting and cultivating them in a fresh culture medium containing M9MM and additives (or LB medium) until early stationary phase. Previous publications showed that this growth phase determined the success of infection in model systems to a strong extend [6-8]. We tested our culture conditions in promoter-reporter assays (Table 1, promoter of the transcription regulator hilA which regulates invasion-related virulence factors [5,9-11] and the response regulator phoP, important for intracellular survival $[12,13])$ and found that the promoter activities reflect published observations confirming our experimental setup.

We tested the following environmental cues for their impact on invasion:

a) Osmotic changes: The food we eat consists predominantly of polymers. During digestion in the small intestine the polymers are cut into many monomers thereby creating more osmotically active compounds. We found that a short-term shift from low to high salt medium increases the invasiveness of Salmonella 24-fold (Figure 1) indicating that a change in osmolarity serves Salmonella as a mark. 
Table 1. Promoter activities of hilA and phoP of selected conditions.

\begin{tabular}{|c|c|c|c|c|c|}
\hline \multirow{3}{*}{$\begin{array}{l}\text { physico-chemical signal } \\
\text { (M9MM + additive) }\end{array}$} & \multicolumn{4}{|c|}{$\%$ promoter activity compared to M9MM \pm standard deviation and regulation $\uparrow / \downarrow / \rightarrow$} & \multirow{3}{*}{ references } \\
\hline & \multicolumn{2}{|r|}{ hilA } & \multicolumn{2}{|r|}{ phoP } & \\
\hline & & $\begin{array}{l}\text { agreement with literature } \\
\text { (yes/no/N.A.) }\end{array}$ & & $\begin{array}{l}\text { agreement with literature } \\
\text { (yes/no/N.A.) }\end{array}$ & \\
\hline $\begin{array}{l}50 \mathrm{mM} \text { magnesium } \\
\text { (positive control) }\end{array}$ & $92 \pm 13 \rightarrow$ & N.A. & $19 \pm 8 \downarrow$ & yes & {$[13,26]$} \\
\hline $\begin{array}{l}\text { short-term osmotic stress } \\
(150 \mathrm{mM} \mathrm{NaCl})\end{array}$ & $159 \pm 4 \uparrow$ & yes & $254 \pm 15 \uparrow$ & N.A. & {$[6,19]$} \\
\hline $\mathrm{pH} 4.5$ & $87 \pm 17 \rightarrow$ & N.A. & $170 \pm 40 \uparrow$ & yes & {$[13,26]$} \\
\hline $5 \mu \mathrm{g} / \mathrm{ml}$ polymyxin B & $142 \pm 3 \uparrow$ & N.A. & $522 \pm 19 \uparrow$ & yes & {$[13,26]$} \\
\hline $0.1 \%$ bile $^{1}$ & $70 \pm 5 \downarrow$ & N.A. & $76 \pm 19 \downarrow$ & N.A. & \\
\hline $1 \%$ glycerol & $159 \pm 20 \uparrow$ & N.A. & $126 \pm 22 \uparrow$ & N.A. & \\
\hline
\end{tabular}

${ }^{1} 50$-fold less bile than in infection assay due to incompatibility of $\mathrm{OD}_{600}$ determination in Miller assay.

b) Influence of bile: Bile, which is secreted from the gall bladder, may indicate Salmonella that it now reaches the habitat of its target cells. Indeed, Salmonella grown in bile prior to infection showed a very effective infection of about 12-fold compared to growth in pure M9MM (Figure 1).

c) Changes in $\mathrm{pH}$ : Along the gastrointestinal tract $\mathrm{pH}-$ values range from neutral or slightly alkaline in the mouth and intestine to acidic in the stomach. Within host cells, the $\mathrm{pH}$ adjusts from neutral to eventually acidic within the "modified" endocytic-lysosomal route of a salmonellacontaining vacuole (SCV) $[2,14,15]$. Figure 1 shows that we could not observe any invasion of Salmonellae grown in slightly acidic medium.

d) Antimicrobial peptides: On the way to its target cells, Salmonella has also to counter the immune system [16], for instance antimicrobial peptides (AMPs), which belong to the first defense line of innate immunity. They are either secreted, for example by epithelial cells, or stored in granules inside phagocytes, which fuse with the phagosome to kill engulfed bacteria. Consequently, AMPs are found extracellular and intracellular. As for $\mathrm{pH} 4.5$, the antimicrobial peptide polymyxin B prevented invasion of HeLa cells (Figure 1).

e) Magnesium ions: Magnesium ions have been shown to negatively act on intracellular survival on genetic level [13] and therefore may promote invasion. We found that bacteria grown with additional magnesium invade cells 3.6-fold better than without this additive (Figure 1).

f) Availability of nutrients and carbon energy: The organic molecules vary from meal to meal and their availability within a cell is different to that in the intestinal lumen. Thus we decided to exchange the carbon source glucose in standard M9MM by 1\% glycerol but its influence on Salmonella's invasion capability was comparatively minor (Figure 1). LB medium is routinely used in

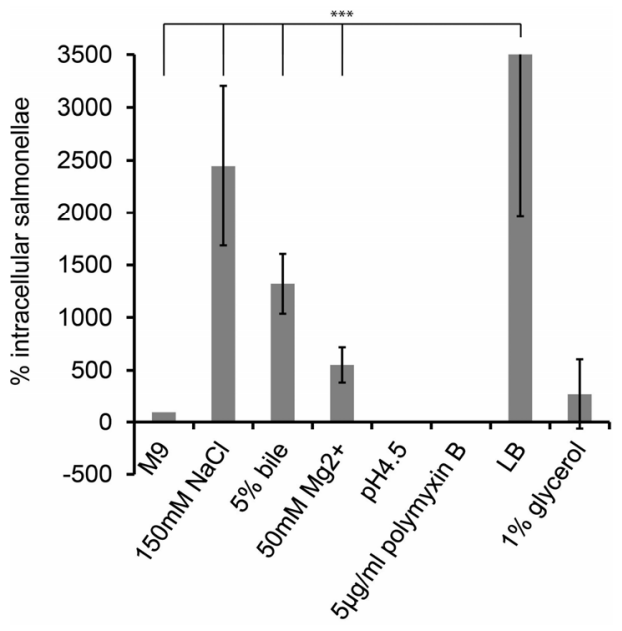

Figure 1. Impact of different growth conditions on invasion. Starter cultures were inoculated in M9MM for a prolonged period. Prior the infection diluted bacteria were grown in M9MM for $3.5 \mathrm{~h}$ with indicated additives. HeLa cells were infected with $10 \mu \mathrm{l}$ bacteria/well of an $\mathrm{OD600}=0.5 \mathrm{for} 20 \mathrm{~min}$. The cfu of this bacterial suspension was determined via plating of dilution series. Invasion was terminated by applying gentamycin for $1 \mathrm{~h}$. To release the intracellular salmonellae, HeLa cells were disrupted with $0.1 \%$ Triton-X100 and the extract was plated onto agar dishes. To take variant bacteria numbers prior infection into account, cfus of intracellular bacteria were normalized against the cfus used for infecting Hela cells. These values were further normalized against the number of intracellular bacteria grown in M9MM. All experiments were run at least three times and error bars indicate standard deviation. The three asterix' indicate a statistically highly significance with $\mathbf{p}<0.001$. M9$\mathrm{MM}=S$. Typhimurim cells grown in M9MM; $150 \mathrm{mM} \mathrm{NaCl}$ = M9MM with additional $150 \mathrm{mM} \mathrm{NaCl} ; 5 \%$ bile = M9MM with $5 \%$ bile; $50 \mathrm{mM} \mathrm{Mg}^{2+}=$ M9MM with $50 \mathrm{mM} \mathrm{MgCl}$; pH 4.5 = M9MM adjusted to $\mathrm{pH} 4.5 ; 5 \mu \mathrm{g} / \mathrm{ml}$ polymyxin $\mathrm{B}=$ M9MM with $5 \mu \mathrm{g} / \mathrm{ml}$ polymyxin B; LB $=S$. Typhimuruim grown in LB medium; 1\% glycerol = 1\% glycerol in M9MM instead of $1 \%$ glucose. 
infection assays $[6,17,18]$ and therefore we tested it, too. Salmonella incubated in the amino acid rich and osmoticcally active LB medium showed a 55-fold higher invasion rate compared to bacteria grown in M9MM and twofold higher invasion rate for bacteria grown to M9MM + $150 \mathrm{mM} \mathrm{NaCl}$.

\section{Discussion}

Usually Salmonella infects its host via the fecal-oral route thereby traveling through certain environmental niches. This includes the escape into the cytosol of an enterocyte eventually. We were interested if Salmonella recognizes these environmental cues which are characteristic for these habitats and responds accordingly. When Salmonella is ingested with food, the latter gets degraded thereby increasing osmolarity which Salmonella may recognize. Indeed, we found that a temporary shift from low to high salt medium enhances the invasiveness of Salmonella dramatically. On molecular level it has been shown that high salt conditions correlate with increased needle complex formation and effector protein secretion virulence determinants essential for invasion [19]. Also, our results are consistent with observations in S. Typhi, where an increasing salt concentration in LB medium positively correlates with an increased invasiveness [20]. During the process of digestion, most sugars (cabonenergy) are absorbed in the upper part of the small intestine whereas peptides are absorbed along the whole small intestine [21]. Regarding Salmonella it has been reported that carbon energy depletion rather than amino acid starvation caused a rapid expression of virulence factors required for invasion [6]. Thus, the complex composition of LB medium of high osmolarity and high levels of amino acids and peptides resembles the digested food mixture of the lumen of the small intestine. It is therefore not surprising that bacteria grown in this medium invade epithelial cells best. Furthermore, bile which is discharged into the small intestine at its entrance served as a strong signal for Salmonella resulting in an effective infection, probably showing that their target cells are in vicinity to their current location. This is contrary to previous reports where bile inhibited invasion [22,23] but there overnight cultures rather than late exponential bacteria were used for infection. A characteristic feature of the intestine may be the decreasing oxygen availability along the gut, but its impact on the invasiveness of Salmonella remains controversial in literature $[7,8,24]$. Surprisingly, the acidic $\mathrm{pH}$ of the stomach does not enhance invasion, although the following body part is the small intestine containing the target cells for Salmonella. We could also show that AMPs abolished invasion of HeLa cells and thus, luminal AMPs serve not as an invasion promoting signal. Interestingly, magnesium ions have been shown to act on the same receptor (phoQ of the two-component system phoP/Q) as AMPs and acidic $\mathrm{pH}$ $[25,26]$. However, AMPs and low $\mathrm{pH}$ direct the upregulation of genes required for intracellular survival (and most likely repress invasion-related virulence factors) but magnesium ions cause an opposite regulatory effect on genetic level [13] which is what we observe phenotypically in our infection assay. Small organic molecules most likely affect the fitness of the bacterium [27] but interestingly, the exchange of the carbon source had a minor influence on Salmonella's invasion capability. In this study we observed a clear correlation between intestinal-relevant cues and invasiveness: A change in osmolarity, bile and a high content on amino acids, characteristic features of the small intestine, increased the invasiveness of Salmonella; whereas a low $\mathrm{pH}$ and antimicrobial peptides, parameters which are also found intracellular abolished invasion. Thus, we conclude that Salmonella modulates its decision between an extra- and intracellular life style in response to a defined set of signals typical for the small intestinal lumen, serving Salmonella as landmarks to prepare for invasion. This study forms the basis for further research for example whether Salmonella is capable to an adaptive prediction of environmental changes. Furthermore, a detailed understanding of the environment and its role in virulence, may lead to a medical application by developing molecules that interfere with Salmonella's decision-making process and therefore interfere with disease.

\section{Materials and Methods}

\subsection{Infection Assay}

Briefly, the gentamicin protection assays were performed incubating the bacteria for approx. $14 \mathrm{~h}, 37^{\circ} \mathrm{C}$ in M9MM and subsequently diluting and cultivating them in a fresh culture medium containing M9MM and additives or adjusted $\mathrm{pH}$ (except where LB medium was used) until early stationary phase $\left(3.5 \mathrm{~h}, 37^{\circ} \mathrm{C}\right)$. To determine the number of living cells used to infect HeLa cells, an aliquot of this bacterial suspension was plated onto agar petri dishes. After a $20 \mathrm{~min}$ infection intracellular salmonellae were recovered and plated on agar petri dishes. The resulting colonies were counted and normalized against the colony forming units (cfu) used to infect the host cells. For percentage calculation recovered bacteria grown in M9MM prior infection were set to $100 \%$.

\subsection{Promoter Reporter Assay}

A classical promoter-reporter assay with lacZ [28] as reporter gene was used along with the promoter of the transcriptional regulator hilA [29] and response regulator phoP [30].

DNA-sequences for the promoters are provided on request. 


\section{Acknowledgements}

We thank Prof. Dr. K. Schnetz (Institute for Genetics, University of Cologne, Germany) and PD Dr. B. Goerke (Department of Microbiology and Genetics, Georg-AugustUniversity of Goettingen, Germany) for kindly providing the plasmids pKES99, pKM04 and pKES. We greatly thank the "Fonds der Chemischen Industrie" for their financial support.

\section{REFERENCES}

[1] J. A. Ibarra and O. Steele-Mortimer, "Salmonella-The Ultimate Insider. Salmonella Virulence Factors that Modulate Intracellular Survival," Cellular Microbiology, Vol. 11, No. 11, 2009, pp. 1579-1586. doi:10.1111/j.1462-5822.2009.01368.x

[2] A. Haraga, M. B. Ohlson and S. I. Miller, "Salmonellae Interplay with Host Cells," Nature Reviews Microbiology, Vol. 6, No. 1, 2008, pp. 53-66. doi:10.1038/nrmicro1788

[3] A. Mitchell, G. H. Romano, B. Groisman, A. Yona, E. Dekel, M. Kupiec, O. Dahan and Y. Pilpel, "Adaptive Prediction of Environmental Changes by Microorganisms," Nature, Vol. 460, No. 7252, 2009, pp. 220-224. doi:10.1038/nature 08112

[4] D. Beier and R. Gross, "Regulation of Bacterial Virulence by Two-Component Systems," Current Opinion Microbiology, Vol. 9, No. 2, 2006, pp. 143-152. doi:10.1016/j.mib.2006.01.005

[5] C. Altier, "Genetic and Environmental Control of Salmonella Invasion," The Journal of Microbiology, Vol. 43, Special Issue, 2005, pp. 85-92.

[6] M. Song, H. J. Kim, E. Y. Kim, M. Shin, H. C. Lee, Y. Hong, J. H. Rhee, H. Yoon, S. Ryu, S. Lim and H. E. Choy, "ppGpp-Dependent Stationary Phase Induction of Genes on Salmonella Pathogenicity Island 1," The Journal of Biological Chemistry, Vol. 279, No. 33, 2004, pp. 34183-34190. doi:10.1074/jbc.M313491200

[7] C. A. Lee and S. Falkow, "The Ability of Salmonella to Enter Mammalian Cells Is Affected by Bacterial Growth State," Proceedings of the National Academy of Sciences of the United States of America, Vol. 87, No. 11, 1990, pp. 4304-4308. doi:10.1073/pnas.87.11.4304

[8] D. A. Schiemann, "Association with MDCK Epithelial Cells by Salmonella Typhimurium Is Reduced during Utilization of Carbohydrates," Infection and Immunity, Vol. 63, No. 4, 1995, pp. 1462-1467.

[9] J. R. Ellermeier and J. M. Slauch, "Adaptation to the Host Environment: Regulation of the SPI1 Type III Secretion System in Salmonella enterica Serovar Typhimurium," Current Opinion in Microbiology, Vol. 10, No. 1, 2007, pp. 24-29. doi:10.1016/j.mib.2006.12.002

[10] B. D. Jones, "Salmonella Invasion Gene Regulation: A Story of Environmental Awareness," The Journal of Microbiology, Vol. 43, Special Issue, 2005, pp. 110-117.

[11] R. L. Lucas, C. P. Lostroh, C. C. DiRusso, M. P. Spector, B. L. Wanner and C. A. Lee, "Multiple Factors Independently Regulate hilA and Invasion Gene Expression in
Salmonella enterica Serovar Typhimurium," Journal of Bacteriology, Vol. 182, No. 7, 2000, pp. 1872-1882. doi:10.1128/JB.182.7.1872-1882.2000

[12] E. Fass and E. A. Groisman, "Control of Salmonella Pathogenicity Island-2 Gene Expression," Current Opinion Microbiology, Vol. 12, No. 2, 2009, pp. 199-204. doi:10.1016/j.mib.2009.01.004

[13] E. A. Groisman and C. Mouslim, "Sensing by Bacterial Regulatory Systems in Host and Non-Host Environments," Nature Reviews Microbiology, Vol. 4, No. 9, 2006, pp. 705709. doi:10.1038/nrmicro1478

[14] O. Steele-Mortimer, "The Salmonella-Containing Vacuole: Moving with the Times," Current Opinion Microbiology, Vol. 11, No. 1, 2008, pp. 38-45. doi:10.1016/j.mib.2008.01.002

[15] O. Steele-Mortimer, S. Meresse, J. P. Gorvel, B. H. Toh and B. B. Finlay, "Biogenesis of Salmonella TyphimuriumContaining Vacuoles in Epithelial Cells Involves Interactions with the Early Endocytic Pathway," Cellular Microbiology, Vol. 1, No. 1, 1999, pp. 33-49. doi:10.1046/j.1462-5822.1999.00003.x

[16] C. A. Muller, I. B. Autenrieth and A. Peschel, "Intestinal Epithelial Barrier and Mucosal Immunity Innate Defenses of the Intestinal Epithelial Barrier," Cellular and Molecular Life Sciences, Vol. 62, No. 12, 2005, pp. 1297-1307. doi:10.1007/s00018-005-5034-2

[17] C. L. Birmingham, A. C. Smith, M. A. Bakowski, T. Yoshimori and J. H. Brumell, "Autophagy Controls Salmonella Infection in Response to Damage to the Salmonella-containing Vacuole," The Journal of Biology Chemistry, Vol. 281, No. 16, 2006, pp. 11374-11383. doi:10.1074/jbc.M509157200

[18] C. R. Beuzon, S. P. Salcedo and D. W. Holden, "Growth and Killing of a Salmonella enterica Serovar Typhimurium sifA Mutant Strain in the Cytosol of Different Host Cell Lines," Microbiology, Vol. 148, No. 9, 2002, pp. 2705-2715.

[19] H. Mizusaki, A. Takaya, T. Yamamoto and S. I. Aizawa, "Signal Pathway in Salt-Activated Expression of the Salmonella Pathogenicity Island 1 Type III Secretion System in Salmonella enterica Serovar Typhimurium," Journal of Bacteriology, Vol. 190, No. 13, 2008, pp. 4624 4631. doi:10.1128/JB.01957-07

[20] C. Tartera and E. S. Metcalf, "Osmolarity and Growth Phase Overlap in Regulation of Salmonella Typhi Adherence to and Invasion of Human Intestinal Cells," Infection and Immunity, Vol. 61, No. 7, 1993, pp. 3084-3089.

[21] W. F. Boron and E. L. Boulpaep, "Medical Physiology: A Cellular and Molecular Approach," 2nd Edition, Saunders Elsevier, Philadelphia, 2009.

[22] A. M. Prouty and J. S. Gunn, "Salmonella enterica Serovar Typhimurium Invasion Is Repressed in the Presence of Bile," Infection and Immunity, Vol. 68, No. 12, 2000, pp. 6763-6769. doi:10.1128/IAI.68.12.6763-6769.2000

[23] C. L. Wells, R. P. Jechorek and S. L. Erlandsen, "Inhibitory Effect of Bile on Bacterial Invasion of Enterocytes: Possible Mechanism for Increased Translocation Associated with Obstructive Jaundice," Critical Care Medicine, 
Vol. 23, No. 2, 1995, pp. 301-307. doi:10.1097/00003246-199502000-00016

[24] J. A. Ibarra, L. A. Knodler, D. E. Sturdevant, K. Virtaneva, A. B. Carmody, E. R. Fischer, S. F. Porcella and O. SteeleMortimer, "Induction of Salmonella Pathogenicity Island 1 under Different Growth Conditions Can Affect Salmonella-Host Cell Interactions in Vitro," Microbiology, Vol. 156, No. 4, 2010, pp. 1120-1133.

[25] M. W. Bader, S. Sanowar, M. E. Daley, A. R. Schneider, U. Cho, W. Xu, R. E. Klevit, H. Le Moual and S. I. Miller, "Recognition of Antimicrobial Peptides by a Bacterial Sensor Kinase," Cell, Vol. 122, No. 3, 2005, pp. 461-472. doi:10.1016/j.cell.2005.05.030

[26] L. R. Prost and S. I. Miller, "The Salmonellae phoQ Sensor: Mechanisms of Detection of Phagosome Signals," Cellular Microbiology, Vol. 10, No. 3, 2008, pp. 576-582. doi:10.1111/j.1462-5822.2007.01111.x
[27] W. Eisenreich, T. Dandekar, J. Heesemann and W. Goebel, "Carbon Metabolism of Intracellular Bacterial Pathogens and Possible Links to Virulence," Nature Reviews Microbiology, Vol. 8, No. 6, 2010, pp. 401-412. doi:10.1038/nrmicro2351

[28] J. H. Miller, "Experiments in Molecular Genetics," Cold Spring Harbor Laboratory, New York, 1972.

[29] L. M. Schechter, S. M. Damrauer and C. A. Lee, "Two AraC/XylS Family Members Can Independently Counteract the Effect of Repressing Sequences Upstream of the hilA Promoter," Moecularl Microbiology, Vol. 32, No. 3, 1999, pp. 629-642. doi:10.1046/j.1365-2958.1999.01381.x

[30] F. C. Soncini, E. G. Vescovi and E. A. Groisman, "Transcriptional Autoregulation of the Salmonella Typhimurium phoPQ Operon," Journal of Bacteriology, Vol. 177, No. 15, 1995, pp. 4364-4371. 